\title{
The Role of Self-Efficacy in the Recovery Process of Stroke Survivors
}

This article was published in the following Dove Press journal:

Psychology Research and Behavior Management

Joanna Szczepańska-

Gieracha (1D'

Justyna Mazurek $\mathbb{D}^{2}$

'Faculty of Physiotherapy, University School of Physical Education in Wroclaw, Wroclaw, Poland; ${ }^{2}$ Department and Division of Medical Rehabilitation, Wroclaw Medical University, Wroclaw, Poland
Correspondence: Justyna Mazurek Department and Division of Medical Rehabilitation, Wroclaw Medical University, Borowska 213, Wroclaw 50-556, Poland Email justyna.mazurek@umed.wroc.pl
Introduction: Belief in one's personal capabilities are conducive to achieving success and provides additional energy for action. The stronger the conviction of one's self-efficacy, the higher the self-goals and the stronger the commitment to achieving them, despite any adversities. Our knowledge regarding the role of self-efficacy in post-stroke rehabilitation is still scarce.

Aim of the Study: The study aimed to analyze characteristics related to high self-efficacy levels before and after rehabilitation and to determine the role of self-efficacy in this process. Materials and Methods: The study involved 99 stroke survivors. Participants' mental and functional state were assessed using Generalized Self-Efficacy Scale (GSES), Barthel Index (BI), Acceptance of Illness Scale (AIS), Geriatric Depression Scale (GDS), Visual Analogue Scale for Pain (VAS), Instrumental Activities of Daily Living (IADL) and Rivermead Mobility Index (RMI). Patients were evaluated twice: on admission $\left(T_{1}\right)$ and 3 weeks into rehabilitation $\left(T_{2}\right)$.

Results: Patients without self-efficacy improvement after 3 weeks of rehabilitation, on discharge from the ward demonstrated poorer well-being ( $p=0.002$, Hedges' $g=0.63$, 95\% CI [0.24-1.08]), lower illness acceptance levels $(p<0.001$, Hedges' $g=-0.78$, $95 \%$ CI $[-1.25--0.41])$, poorer functional status in basic activities of daily living ( $p=$ 0.003 , Hedges' $g=-0.62,95 \%$ CI $[-1--0.25])$, locomotive abilities $(p=0.004$, Hedges' $g=-0.58,95 \%$ CI $[-1.12--0.15])$ and instrumental activities of daily living ( $p=0.001$, Hedges' $g=-0.71,95 \%$ CI $[-1.15--0.34])$.

Conclusion: Self-efficacy level is significantly related to rehabilitation outcomes. A routine self-efficacy assessment during the rehabilitation process seems very important. Patients whose initial self-efficacy is low or remains unchanged despite rehabilitation require special attention. Close cooperation between all members of the therapeutic team is essential to strengthen, at each stage, the sense of self-efficacy in stroke survivors.

Keywords: self-efficacy, rehabilitation outcomes, depression, acceptance of illness, behavior management

\section{Introduction}

Sudden change in the life of people after stroke can lead to a wide range of negative psychological and behavioral symptoms, including anxiety, feeling of helplessness and mood disorders. ${ }^{1}$ Most patients must face various functional, mental, and social constraints. Reduced mobility is a serious problem, as it hinders the performance of everyday tasks and results in isolation due to job loss and inability to resume prestroke leisure activities. Deterioration of the quality of life is inevitable ${ }^{2}$ and often leads to depression. ${ }^{3}$

Belief in one's personal capabilities is conducive to achieving success and provides additional energy for action. The stronger the conviction of one's self-efficacy, the 
higher the self-goals and the stronger the commitment to achieving them, even in the face of adversities. ${ }^{4}$ On the other hand, a low sense of self-efficacy is associated with depression, anxiety and helplessness, while a lack of selfefficacy can completely reduce one's motivational potential. The sense of self-efficacy differentiates people in terms of thinking, feeling and acting. ${ }^{5}$

Assessing the level of self-efficacy and working to improve this characteristic can help stroke survivors gain greater control over many important aspects of their disease and improve their chances for better and more sustained rehabilitation effects. There has been growing evidence that interventions aimed at increasing selfefficacy have a significant impact on the efficacy of chronic illness therapy, including stroke therapy, and that physiotherapists may have an important role to fulfill in the process. ${ }^{6-8}$

Such an approach fits well with the biopsychosocial model of illness, particularly in the context of patientcentred care. There is now a wealth of evidence supporting its validity as a powerful holistic model which, by increasing attention upon the patient as a person and requiring greater collaboration and sharing of care and resources, has the potential to contribute to a more successful and sustainable healthcare system. ${ }^{9}$ Therefore, the purpose of our study was to analyze the characteristics related to high self-efficacy levels before and after rehabilitation and to determine the role of self-efficacy in the rehabilitation process.

\section{Materials and Methods Study Group}

The study was carried out at a neurological rehabilitation ward in the Silesian Rehabilitation Centre, Poland. The study was conducted for a year and during this time all the successively admitted patients who met the inclusion criteria were qualified to take part. The inclusion criteria were as follows: first ischemic brain stroke, no symptoms of dementia (Mini-Mental State Examination, MMSE $\geq 24$ ) and over 50 years of age. The applied exclusion criteria were as follows: no possibility of performing a cognitive function examination (due to severe loss of vision or aphasia), a history of prior stroke, the presence - at examination or in medical records - of intellectual disability, consciousness disorders or other severe mental disorders, as well as addiction to medication or other psychoactive substances. Participation in the study was entirely voluntary, the patients provided their written consent prior to enrolment and were informed that they could leave the research project at any given moment, without consequences to their clinical care. All the participants understood the study purpose. The study received approval from the Scientific Research Ethics Committee (reference number: 30/2017) at the University School of Physical Education in Wroclaw, Poland in December 2017 and was conducted in accordance with the Declaration of Helsinki.

One hundred participants were qualified for the study. They were evaluated twice: on admission $\left(T_{1}\right)$ and 3 weeks into rehabilitation $\left(\mathrm{T}_{2}\right)$. Full assessment at both measurement points was obtained in 99 patients. Mean age of the respondents was 61 years $(S D=6.2)$ and $58.6 \%$ of the study group were men. Most of the participants (64.6\%) lived in a city and were admitted to the rehabilitation ward from home (63.6\%). Mean period since stroke was 17 days. Among the study group, $56.6 \%$ of the respondents were married and $45.5 \%$ declared their families to have full care capacity. Slightly over a half of the participants (53.5\%) were retired. Fifty-four point five percent of the group had secondary or higher education. Fifty-six point six percent performed physical work (eg, farmer, car mechanic, cleaner, electrician) and $43.4 \%$ were mental workers (eg, office worker, accountant, teacher). Leftsided paresis prevailed in the study group (58.6\%). Only $26.3 \%$ of the patients had no comorbidities while $18.2 \%$ had one additional illness and $55.5 \%$ of patients had two or more additional chronic illnesses. Mean Body Mass Index (BMI) score was $27.2(S D=3.3)$ among the examined women and $28.9(S D=3.1)$ among the men. Detailed sociodemographic and clinical data are presented in Table 1.

\section{Methods}

The primary research tool was the Generalized SelfEfficacy Scale (GSES) which refers to the concept of selfefficacy as formulated by its creator, Albert Bandura. The scale consists of 10 statements aimed at assessing an individual's perceived ability to cope in difficult situations and overcome obstacles. The higher the score, the greater the sense of self-efficacy. ${ }^{10,11}$

Level of acceptance of illness was measured using the Acceptance of Illness Scale (AIS). The instrument consists of eight items describing the consequences of poor health and illness. The statements acknowledge the constraints imposed by illness, lack of self-sufficiency, the sense of dependence on others and reduced self-esteem. The higher 
Table I Sociodemographic Characteristics of the Study Group

\begin{tabular}{|c|c|c|}
\hline \multicolumn{2}{|l|}{ Variables } & \multirow{2}{*}{$\begin{array}{l}\text { (\%) } \\
41 \\
58\end{array}$} \\
\hline Gender & $\begin{array}{l}\text { Female } \\
\text { Male }\end{array}$ & \\
\hline Dwelling place & $\begin{array}{l}\text { City } \\
\text { Rural area }\end{array}$ & $\begin{array}{l}64 \\
35\end{array}$ \\
\hline Admitted from & $\begin{array}{l}\text { Home } \\
\text { Hospital }\end{array}$ & $\begin{array}{l}63 \\
36\end{array}$ \\
\hline Occupational status & $\begin{array}{l}\text { Disability pension } \\
\text { Retirement pension } \\
\text { Employed } \\
\text { Unemployed }\end{array}$ & $\begin{array}{l}18 \\
53 \\
22 \\
6\end{array}$ \\
\hline Education & $\begin{array}{l}\text { Primary } \\
\text { Vocational } \\
\text { Secondary } \\
\text { Higher }\end{array}$ & $\begin{array}{l}15 \\
30 \\
34 \\
20\end{array}$ \\
\hline Work type before stroke & $\begin{array}{l}\text { Physical } \\
\text { Mental }\end{array}$ & $\begin{array}{l}56 \\
43\end{array}$ \\
\hline Marital status & $\begin{array}{l}\text { Single } \\
\text { Married } \\
\text { Widow/widower }\end{array}$ & $\begin{array}{l}18 \\
56 \\
25\end{array}$ \\
\hline Family care capacity & $\begin{array}{l}\text { Lack } \\
\text { Incomplete } \\
\text { Full }\end{array}$ & $\begin{array}{l}21 \\
33 \\
45\end{array}$ \\
\hline
\end{tabular}

the score, the better the adjustment to illness, which is manifested by the absence of negative illness-related emotions. $^{12}$

The sense of well-being and mood of the participants were measured with the Geriatric Depression Scale (GDS30). In this scale, a score above 10 indicates depression, with the severity of symptoms increasing along with the score. ${ }^{13}$ Pain intensity was measured using the Visual Analogue Scale for Pain (VAS) with two verbal descriptors, "no pain" for the score of 0 and "worst pain imaginable" for the score of 10 .

The Barthel Index (BI) was used to assess the participants' functional state in terms of basic activities of daily living $^{14}$ and the Instrumental Activities of Daily Living (IADL) Scale for more complex tasks. ${ }^{15}$ Patient mobility was evaluated with the Rivermead Mobility Index (RMI). ${ }^{16}$ In all the above scales, the higher the score, the better the patient's functioning.

All assessments were performed at two measuring points: within two days of admission to the ward $\left(T_{1}\right)$ and after 3 weeks of neurological rehabilitation $\left(\mathrm{T}_{2}\right)$.
Participants assessed their family care capacity (FCC) only once, on admission $\left(\mathrm{T}_{1}\right)$, rating it as: ' 0 ' - lack of capacity, ' 1 ' - incomplete capacity (the family is able to provide care on a limited basis) and ' 2 ' - full care capacity of the family. A cut-off point of 60 years of age was adopted to assess the differences between the older and younger patients.

The efficacy of rehabilitation was assessed in a dichotomous division, where in case of improvement, its extent was assessed (a number of points on an appropriate scale), and other outcomes (lack of improvement or regress) were assigned the value of 0 . With the applied method of assessment of rehabilitation efficacy, the number of 0 scores was relatively large and, in consequence, the distribution of point assessments for improvement was decidedly skewed.

\section{Post-Stroke Rehabilitation}

Neurological rehabilitation was carried out in hospital setting at a neurological rehabilitation ward. The rehabilitation program was designed individually for each patient due to the varying levels of functional ability on admission. However, the amount of therapy received (the duration of a single session and number of rehabilitation sessions per week) was the same for each participant and included the following activities: individual exercises taking into account individual neurological and functional deficits, active and passive kinesitherapy of upper and lower limbs, balance and gait re-education exercises, hydrotherapy and electrostimulation. Physiotherapy (run by a physiotherapist) was combined with occupational therapy run by an occupational therapist. Participants also received psychological support which included a diagnosis of cognitive function, and emotional support if the psychologist deemed it necessary.

\section{Statistical Methods}

Statistical description of characteristics with continuous distributions included determination of mean values and standard deviations. Distributions of characteristics with discrete distributions were presented as distribution series. The Kolmogorov-Smirnov test was used to verify the normality of distribution of continuous characteristics. Parametric testing (Student's $t$-test for independent samples) was used to assess differences between mean values and the single-factor variance analysis (ANOVA) to compare a greater number of means. Correlations between characteristics were assessed by determination of the 
Pearson's $r$ linear correlation coefficient. With the null hypothesis on the normality of distribution rejected, correlation was assessed by determining the Spearman's rank correlation coefficient $(\rho) .^{17}$

The correlation of the observed GSES score improvement with the improvement in each of the other scales was assessed using the non-parametric Spearman's rank correlation coefficient. Verification of the null hypotheses was performed at the critical level of $p<0.05$. All calculations were carried out using the STATISTICA 13.3 software by Dell.

\section{Results}

\section{The Sense of Self-Efficacy on Admission to the Ward}

At $\mathrm{T}_{1}$ there was no significant difference between men and women in terms of self-efficacy ( $p=0.62$, Hedges' $g=-0.098,95 \%$ CI $[-0.51--0.31])$. However, a difference was observed between the older and younger patients. Selfefficacy was significantly higher in people aged 60 years and older ( $p=0.02$, Hedges' $g=-0.63,95 \%$ CI $[-1.12-$ $-0.23])$. No link was detected between the sense of selfefficacy and education or the type of performed work. There was, however, a statistically significant relationship between the mean self-efficacy and marital status $(p<$ 0.001$, Ges $=0.325,95 \%$ CI $[0.18-0.45])$ of participants as well as care capacity of their families $(p<0.001$, Ges $=$ $0.323,95 \%$ CI [0.17-0.45]). The lowest self-efficacy level was found in participants who were single and whose families lacked care capacity, and the highest in people who were married and had families with full care capacity (Table 2).

\section{The Efficacy of Post-Stroke Rehabilitation}

After three weeks of post-stroke rehabilitation, we recorded a significant improvement in almost all of the parameters analyzed. One exception was the level of depression, where no significant changes were recorded. The change of self-efficacy was statistically significant ( $p=0.0002$, Hedges' $g=0.36$, 95\% CI [0.17-0.56]). Improvement of the self-efficacy correlated significantly with a reduction of depressive symptoms, an increase in illness acceptance level and an improvement in terms of basic activities of daily life (Table 3 ). The highest number of cases of improvement in the self-efficacy was recorded in participants with higher education who were married, whose families had full care capacity, and who had performed mental type of work before stroke (Figure 1).

Table 2 The Relationship Between the Value of Self-Efficacy and the Sociodemographic Characteristics on Admission to the Ward $\left(\mathrm{T}_{1}\right)$

\begin{tabular}{|c|c|c|c|c|}
\hline Characteristics & Category & $M \pm S D$ & p | post hoc & Effect size $[95 \% \mathrm{Cl}]^{*}$ \\
\hline Gender & $\begin{array}{l}\text { Female } \\
\text { Male }\end{array}$ & $\begin{array}{l}27.9 \pm 10.0 \\
28.8 \pm 9.2\end{array}$ & 0.62 & $\begin{array}{l}-0.098 \\
{[-0.51--0.31]}\end{array}$ \\
\hline Age & $\begin{array}{l}\geq 60 \\
>60\end{array}$ & $\begin{array}{l}25.5 \pm 10.0 \\
31.3 \pm 8.1\end{array}$ & 0.02 & $\begin{array}{l}-0.63 \\
{[-1.12--0.23]}\end{array}$ \\
\hline Education & $\begin{array}{l}\text { Primary } \\
\text { Vocational } \\
\text { Secondary } \\
\text { Higher }\end{array}$ & $\begin{array}{l}29.5 \pm 10.5 \\
27.5 \pm 7.4 \\
26.8 \pm 10.1 \\
31.8 \pm 10.2\end{array}$ & 0.266 & $\begin{array}{l}0.041 \\
{[0-0.12]}\end{array}$ \\
\hline Work type before stroke & $\begin{array}{l}\text { Physical } \\
\text { Mental }\end{array}$ & $\begin{array}{l}27.5 \pm 8.8 \\
29.7 \pm 10.3\end{array}$ & 0.248 & $\begin{array}{l}-0.23 \\
{[-0.68-0.17]}\end{array}$ \\
\hline Marital status & $\begin{array}{l}\text { Single }^{\mathrm{a}} \\
\text { Married }^{\mathrm{b}} \\
\text { Widow/widower }^{\mathrm{c}}\end{array}$ & $\begin{array}{l}18.1 \pm 7.3 \\
32.4 \pm 7.2 \\
27.0 \pm 9.5\end{array}$ & $\begin{array}{l}\text { a vs } b<0.001 \\
a \text { vs } c 0.0011 \\
b \text { vs c } 0.015\end{array}$ & $\begin{array}{l}0.325 \\
{[0.18-0.45]}\end{array}$ \\
\hline Family care capacity & $\begin{array}{l}\text { Lack }^{\mathrm{a}} \\
\text { Incomplete }^{\mathrm{b}} \\
\text { Full }^{\mathrm{c}}\end{array}$ & $\begin{array}{l}19.3 \pm 7.3 \\
27.5 \pm 9.3 \\
33.3 \pm 7.0\end{array}$ & $\begin{array}{l}\text { a vs } b<0.001 \\
\text { a vs c }<0.001 \\
\text { b vs c } 0.005\end{array}$ & $\begin{array}{l}0.323 \\
{[0.17-0.45]}\end{array}$ \\
\hline
\end{tabular}

Notes: Tests: Student's t-test (with two groups) or ANOVA (for more than two groups) with Tukey HSD post hoc analysis, Effect size - *Hedges' g (for two groups), Ges: generalized eta squared (for more than two groups). 
Table 3 The Efficacy of Post-Stroke Rehabilitation After the First 3 Weeks of Participants' Stay at the Ward

\begin{tabular}{|c|c|c|c|c|c|}
\hline Characteristics & $\begin{array}{l}\text { Time } \\
\text { point }\end{array}$ & $M \pm S D$ & $\begin{array}{l}\text { Mean change } \\
(95 \% \mathrm{Cl})\end{array}$ & $\begin{array}{l}\text { p (Wilcoxon test) } \\
\text { effect size }[95 \% \mathrm{Cl}]\end{array}$ & $\begin{array}{l}\text { Association with Self-Efficacy } \\
\text { Improvement OR ( } 95 \% \mathrm{Cl})\end{array}$ \\
\hline Depression & $\begin{array}{l}\mathrm{T}_{1} \\
\mathrm{~T}_{2}\end{array}$ & $\begin{array}{l}8.10 \pm 5.85 \\
7.84 \pm 6.20\end{array}$ & $\begin{array}{l}-0.26 \\
(-0.8 I-0.28)\end{array}$ & $\begin{array}{l}0.2978 \\
-0.096[-0.31-0.1]\end{array}$ & $\begin{array}{l}4.61 \\
(2.00-11.1)\end{array}$ \\
\hline Acceptance of illness & $\begin{array}{l}\mathrm{T}_{1} \\
\mathrm{~T}_{2}\end{array}$ & $\begin{array}{l}23.44 \pm 9.13 \\
25.16 \pm 9.96\end{array}$ & $\begin{array}{l}1.72 \\
(0.88-2.54)\end{array}$ & $\begin{array}{l}0.0001 \\
0.41[0.21-0.63]\end{array}$ & $\begin{array}{l}4.31 \\
(1.86-10.5)\end{array}$ \\
\hline Pain & $\begin{array}{l}\mathrm{T}_{1} \\
\mathrm{~T}_{2}\end{array}$ & $\begin{array}{l}0.94 \pm 2.26 \\
0.69 \pm 1.75\end{array}$ & $\begin{array}{l}-0.25 \\
(-0.39--0.11)\end{array}$ & $\begin{array}{l}0.0015 \\
-0.36[-0.47--0.26]\end{array}$ & $\begin{array}{l}0.35 \\
(0.07-1.22)\end{array}$ \\
\hline Self-efficacy & $\begin{array}{l}T_{1} \\
T_{2}\end{array}$ & $\begin{array}{l}28.43 \pm 9.49 \\
29.86 \pm 9.95\end{array}$ & $\begin{array}{l}1.42 \\
(0.65-2.20)\end{array}$ & $\begin{array}{l}0.0002 \\
0.36[0.17-0.56]\end{array}$ & - \\
\hline $\begin{array}{l}\text { Basic activities } \\
\text { of daily living }\end{array}$ & $\begin{array}{l}\mathrm{T}_{1} \\
\mathrm{~T}_{2}\end{array}$ & $\begin{array}{l}55.66 \pm 16.56 \\
69.49 \pm 13.97\end{array}$ & $\begin{array}{l}13.84 \\
(11.39-16.29)\end{array}$ & $\begin{array}{l}<0.0001 \\
1.13[0.96-1.32]\end{array}$ & $\begin{array}{l}6.31 \\
(2.16-23.2)\end{array}$ \\
\hline Mobility & $\begin{array}{l}\mathrm{T}_{1} \\
\mathrm{~T}_{2}\end{array}$ & $\begin{array}{l}6.96 \pm 2.32 \\
8.78 \pm 1.92\end{array}$ & $\begin{array}{l}1.82 \\
(1.45-2.19)\end{array}$ & $\begin{array}{l}<0.0001 \\
0.99[0.66-1.39]\end{array}$ & $\begin{array}{l}3.9 \\
(1.3-14.5)\end{array}$ \\
\hline $\begin{array}{l}\text { Instrumental activities } \\
\text { of daily living }\end{array}$ & $\begin{array}{l}\mathrm{T}_{1} \\
\mathrm{~T}_{2}\end{array}$ & $\begin{array}{l}17.00 \pm 4.12 \\
18.48 \pm 3.53\end{array}$ & $\begin{array}{l}1.48 \\
(1.12-1.85)\end{array}$ & $\begin{array}{l}<0.0001 \\
0.82[0.67-0.98]\end{array}$ & $\begin{array}{l}1.39 \\
(0.63-3.12)\end{array}$ \\
\hline
\end{tabular}

Notes: $T_{1}-$ first measuring point (on admission), $T_{2}-$ second measuring point (after 3 weeks of rehabilitation), *Hedges' $g$.

\section{Change in Self-Efficacy During Rehabilitation}

In the final part of the statistical analysis, the study group was divided into two subgroups: participants with improvement in the self-efficacy after 3 weeks of rehabilitation $(n=43)$ and participants without such improvement $(n=56)$. Statistical analysis showed that the first group had a significantly better mental and functional state at $T_{2}$ in all the characteristics studied. The sole exception was the level of pain sensations (Table 4).

No significant relationship was detected between the improvement in self-efficacy and such clinical data as the side of paresis or number of comorbidities. By comparing sociodemographic characteristics in participants who achieved improvement in self-efficacy after the threeweek rehabilitation $(n=43)$ and in those without such improvement $(n=56)$, we found that a significant difference between the groups is only visible for the level of the family care capacity $(p=0.021, \mathrm{OR}=3.53,95 \% \mathrm{CI}$ [1.08-11.51]). A self-efficacy improvement occurred most frequently in those participants whose families had full care capacity.

\section{Discussion}

Many authors have confirmed the importance of selfefficacy as a self-regulatory mechanism in various chronic diseases, such as cancer, infectious diseases, neurodegenerative diseases or cystic fibrosis. Patients with high selfefficacy values are better at coping with the negative consequences of their disease and with its treatment. ${ }^{18-21}$ The importance of self-efficacy seems even greater in the case of diseases that limit physical function and require long-term rehabilitation. The stronger the conviction of one's self-efficacy, the higher the self-goals one sets for oneself and the stronger the commitment to achieving them. ${ }^{4}$ Such a goal may be to regain full physical fitness or to return to one's professional and social roles from before the onset of the disease.

The level of self-efficacy is based on life experience and contains aspects of the patient's pre-disease identity. Therefore, in this study, we tried to determine which sociodemographic characteristics are related to selfefficacy. Statistical analysis demonstrated that participants who were older (over 60 years of age), married participants and those whose families had a full care capacity obtained higher self-efficacy scores prior to rehabilitation. Interestingly, two of these characteristics (marital status and family care capacity) are related to patients' social situation and not their internal, psychological resources. It appears that younger people (between 50 and 60 years of age) experience a greater loss due to stroke than older patients, especially those who are already retired. For 


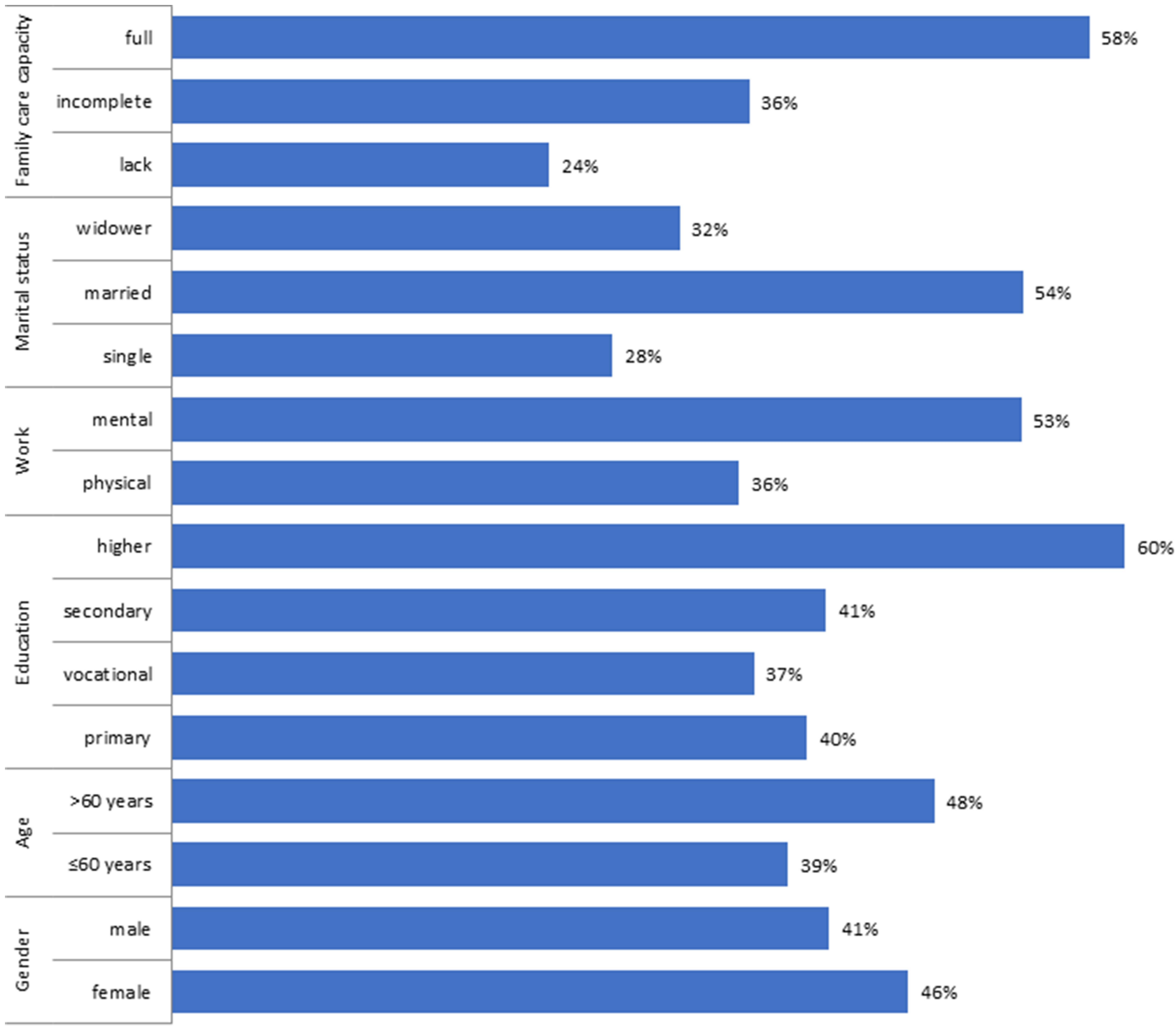

Figure I Percentage of cases of improved sense of self-efficacy after post-stroke rehabilitation. As the percentage values were determined in relation to the size of each category of characteristics, they do not add up to $100 \%$ within each characteristic.

younger, professionally active people stroke means not only the loss of independence, but also the loss of the possibility to continue working in their profession, whereas the age of $50+$ years may be a period of intense activity, both professional and social. The problem affects both people in physical jobs (eg, farmer, mechanic,

Table 4 Functional and Mental State of Participants After 3 Weeks of Post-Stroke Rehabilitation in Groups of Patients with and without Improvement in Self-Efficacy

\begin{tabular}{|c|c|c|c|c|c|}
\hline \multirow[t]{2}{*}{ Characteristics } & \multicolumn{3}{|l|}{ Self-efficacy } & \multirow[t]{2}{*}{$\mathrm{g}[95 \% \mathrm{Cl}]$} & \multirow[t]{2}{*}{$p$} \\
\hline & No Improvement M \pm SD & Improvement $\mathbf{M} \pm \mathrm{SD}$ & Mean diff. $(95 \% \mathrm{Cl})$ & & \\
\hline Depression & $9.48 \pm 6.24$ & $5.70 \pm 5.52$ & $3.78(1.43-6.13)$ & $0.63[0.24-1.08]$ & 0.002 \\
\hline Acceptance of illness & $22.00 \pm 9.73$ & $29.28 \pm 8.75$ & $-7.28(-10.98--3.58)$ & $-0.78[-1.25--0.4 \mid]$ & $<0.001$ \\
\hline Pain & $0.88 \pm 1.95$ & $0.44 \pm 1.45$ & $0.43(-0.24-1.11)$ & $0.25[-0.11-0.64]$ & 0.225 \\
\hline Basic activities & $65.89 \pm 14.59$ & $74.19 \pm 11.70$ & $-8.29(-13.54--3.05)$ & $-0.62[-1--0.25]$ & 0.003 \\
\hline Mobility & $8.30 \pm 1.80$ & $9.40 \pm 1.92$ & $-1.09(-1.84--0.34)$ & $-0.58[-1.12--0.15]$ & 0.004 \\
\hline Instrumental activities & $17.46 \pm 3.83$ & $19.81 \pm 2.58$ & $-2.35(3.63--1.07)$ & $-0.71[-1.15--0.34]$ & 0.001 \\
\hline
\end{tabular}

Notes: g - Effect size (Hedges' g), p - Student's t-test. 
cleaner), due to physical disability, and those performing mental type of work (eg, office worker, accountant, teacher), due to impaired concentration and deficits in cognitive functions. Finding support in one's spouse or family can be very important in dealing constructively with such a difficult situation.

The situation is quite similar when we look at who has the best chance of improving self-efficacy during rehabilitation. These will still be the patients who are married and whose families have a full family care capacity, but also people with higher education and those who did mental type of work before the stroke. This is probably due to the fact that after stroke, one must try to look for new ways of coping in daily life. This is perhaps easier for the so-called white-collar workers, ie, people working in positions where they have to manage others, as they are used to facing new situations and solving various problems for their whole team. It might also be easier for such people to find solutions to their own problems by searching for sources of knowledge on the Internet or in medical publications. The fact of seeking knowledge and following the example of other people who have coped with a similar problem is the determinant of an active fight against the disease and has a better chance of success than a passive attitude.

Thus, on admission to rehabilitation wards particular attention should be paid to younger patients without family support and those working in low-education jobs. Korpershoek et al state that interventions aimed at increasing the sense of self-efficacy, such as task-oriented walking group exercise program and group education intervention are effective and contribute to improvement of various patient outcomes, resulting in better mobility, independence in activities of daily living, lower risk of depression and higher quality of life. ${ }^{22}$ Therefore, patients falling into the categories mentioned above should, first and foremost, participate in such self-efficacy improvement interventions. In a study by Gillham et al, patients after stroke who received "enhanced secondary prevention" (additional advice, motivational interviewing and telephone support) to change health behavior achieved significant improvements for change in a self-reported exercise $(p=0.007){ }^{23}$ There is evidence that a stroke survivor's internal drive, resilience, and sense of selfefficacy play a role in adopting good behaviors. ${ }^{24}$ What is more, engagement in a stroke-specific self-management program can improve client-perceived occupational performance and satisfaction. Self-efficacy was shown to be a mediating variable to occupational performance improvements. ${ }^{25}$ This fact seems extremely important in the case of younger stroke survivors who still have a good chance and the need to return to professional activity.

In their study, Torrisi et al demonstrated that rehabilitation outcomes and self-efficacy levels may significantly influence the level of mood, but not vice versa. The lowest levels of depression were detected in stroke survivors in good functional state after a completed physiotherapy, who demonstrated a high sense of self-efficacy. Neither logopedic nor neuropsychological treatment was provided in this study. ${ }^{26}$ Volz et al proved that a low self-efficacy level is a driving factor for depression during the first two years post-stroke. It follows that the impact of self-efficacy on depressive symptoms is stronger than the other way round. Their results show the crucial role of declining selfefficacy in the emergence of depression after stroke. ${ }^{27}$ Robinson-Smith et al have shown that patients with low self-efficacy scores have higher levels of depression, both at one and six months after stroke, and that higher selfefficacy is also significantly correlated with higher quality of life. ${ }^{28}$

In our study, we looked at the concept of self-efficacy also in terms of the change that occurs during rehabilitation. We found that participants who did not show an improvement in self-efficacy after 3 weeks of treatment had poorer well-being, lower levels of illness acceptance and poorer functional status. Our findings are consistent with the results obtained by Volz et al, who concluded that dissatisfaction with recovery after stroke might lead to decreased self-efficacy. ${ }^{29}$ The results presented above were also confirmed in a systematic literature review that demonstrated self-efficacy to be positively linked to better mobility, greater independence in daily life activities and better quality of life, and to be negatively linked to the level of post-stroke depression. ${ }^{22}$ Crucial findings were published by Svendsen et al who compared patients with stroke who underwent rehabilitation and those who were provided with "usual care". The authors found that after 12-22 years after stroke, the group who had taken part in rehabilitation showed a significantly higher level of selfefficacy and had higher quality of life than the group who had not undergone a rehabilitation program. ${ }^{30}$

It therefore seems that a high level of self-efficacy allows for more effective solutions and strategies to be applied in the recovery process. For this reason, interventions aimed at increasing self-efficacy and concerning stroke survivors should be included in the daily program 
carried out by physiotherapists working with this group of patients. Current British guidelines regarding procedure to be applied after stroke explicitly recommend that patients participate in "self-management programs based on selfefficacy". 31 That is why physiotherapists should not only focus on the physical, but also psychological and social aspects in the process of recovery. ${ }^{32}$ Such an approach is indeed possible if the specialists involved in treating a stroke survivor constitute an actual, cooperating team where the members share information and observations regarding the patient and his or her needs and where they together plan and execute the rehabilitation process in line with the biopsychosocial model. Going beyond standard methods at each stage of rehabilitation and handing over to the patient increasingly more responsibility for the course of this process are the pillars of patient-centered care.

Patient safety is an important element in this approach, as strict procedures usually guarantee greater safety, but fail to take into account differences between stroke survivors and restrict the involved specialists in developing an individual approach to each patient. Clearly defined therapeutic procedures are also intended to protect workers from being held responsible for possible accidents. Stroke impairs locomotive abilities and leads to balance and coordination disorders which, if combined with disorders of cognition and visual-spatial perception or aphasia, make for a very complicated rehabilitation process where accidents (mostly falls) are not uncommon. And that is exactly why actual cooperation of the therapeutic team, holistic approach to the patient and joint risk-taking are so important. Tasks assigned to the patient should be a challenge requiring effort but not exceeding the patient's capabilities and should, as much as possible, reflect the tasks he or she will have to face on return home. Therefore, knowledge of the conditions in which stroke survivors function in their natural environment is extremely important to prepare them well for leaving the rehabilitation ward. It has been found that, with adequate support from the therapeutic team, even the oldest patients are able to quickly recover the skills necessary for daily living (especially those who cannot count on anyone's help at home). ${ }^{33}$

\section{Clinical Recommendations Based on Study Findings}

At present, the issue of self-efficacy in stroke survivors is still too rarely taken into account in their rehabilitation process. Physiotherapy is largely medication-based and strictly supervised by qualified medical staff. However, at each stage of post-stroke rehabilitation, it is possible to develop a number of exercises and tasks that are quite safe for the patient and to entrust him or her with the responsibility to perform them every day after the scheduled rehabilitation routine. Thanks to such a model, the patient receives tools to be used also after leaving the rehabilitation ward, as well as the valuable awareness that he or she can actively participate in the physiotherapy process and not just follow a specialist's instructions. It is not our suggestion to create completely new rehabilitation procedures to replace the existing ones, but to give the specialist team working together with an opportunity to develop an individual rehabilitation plan for each patient, because stroke survivors are very different from each other, depending on the extent of the ischemic lesion and its location in the brain, and consequently, the range of functional, cognitive and emotional problems that affect them.

We fully agree with Korpershoek's statement that

the management of stroke units in hospitals, rehabilitation centres and nursing homes need to facilitate the use of self-efficacy in the daily care. They need to create time, space and financial support in their policy to make it possible for nurses to offer patients the opportunity to learn about self-efficacy, practise and share experiences with other patients. ${ }^{22}$

In our opinion, similar tasks should be given to physiotherapists and occupational therapists. A routine selfefficacy assessment on admission to a rehabilitation unit appears even more important than assessment of the level of depression. In the case of depression, pharmacotherapy often becomes the easiest solution, which unfortunately robs patients of control over their own mental state. In our view, first priority should be given to interventions aimed at increasing self-efficacy in the rehabilitation process, as there is a high probability that improvement in the functional state will result in reduction of depressive symptoms. From a psychological perspective, such a situation is preferable, because the change is related directly to the patient's own activity, and not to psychoactive drugs.

\section{Limitations}

The greatest limitation of our study was the lack of longterm self-efficacy assessment in the recovery process after 
stroke. That is why it would be important to carry out further multi-center studies, taking into account different methods and models of rehabilitation and allowing for longer observation of the rehabilitation process. Another limitation of the presented study could be selection bias. The study included only individuals with ischemic stroke and without previous history of stroke, meaning that no patients with hemorrhagic stroke or with multiple stroke episodes were examined. As epidemiological data show that they constitute a significant proportion of patients with stroke, the study group should be expanded in the future to include a representative sample of the entire population of stroke survivors. Another limitation is using the Generalized Self-Efficacy Scale which refers directly to the definition created by A. Bandura, while there is another available tool, ie, the Stroke Self-Efficiency Questionnaire which refers to situations related to stroke. It would be worthwhile if future studies used the latter questionnaire and compared the obtained findings.

\section{Conclusions}

The self-efficacy level is significantly related to the process of rehabilitation. On admission to rehabilitation wards particular attention should be paid to younger patients (under 60 years of age), without family support and working in low-education jobs. It seems necessary to reformulate the objectives of rehabilitation so that strengthening the sense of self-efficacy becomes the key task in the process of rehabilitation aimed at regaining self-sufficiency and improving life management skills. A routine self-efficacy assessment on commencement and completion of rehabilitation at a hospital ward seems legitimate and important. On discharge from the ward, patients whose initial self-efficacy level was low and remained unchanged during rehabilitation should receive special attention. The development of scientific evidence-based interventions aimed at increasing selfefficacy in stroke survivors is an important challenge faced by today's post-stroke rehabilitation. Future research projects should focus on further exploration of strategies facilitating self-efficacy during stroke selfmanagement programs in order to maximize the effects of rehabilitation.

\section{Disclosure}

The authors report no conflicts of interest for this work.

\section{References}

1. Kobylańska M, Kowalska J, Neustein J, et al. The role of biopsychosocial factors in the rehabilitation process of individuals with a stroke. WORK. 2019;61(4):523-535. doi:10.3233/WOR-162823

2. Burton CR. A description of the nursing role in stroke rehabilitation. $J$ Adv Nurs. 2000;32:174-181.

3. Hofmann SG, Curtiss J, Carpenter JK, Kind S. Effect of treatments for depression on quality of life: a meta-analysis. Cognitive Behaviour Therapy. 2017;46(4):265-286. doi:10.1080/16506073.2017.1304445

4. Locke EA, Latham GP. A Theory of Goal Setting and Task Performance. New York: Prentice Hall; 1990.

5. Bandura AA. Self-efficacy: toward a unifying theory of behavioral change.. Psychol Rev. 1977;84(2):191-215. doi:10.1037/0033295X.84.2.191

6. Jones F, Riazi A. Self-efficacy and self-management after stroke: A systematic review. Disabil Rehabil. 2011;33(10):797-810. doi:10.3109/09638288.2010.511415

7. Jones F. Strategies to enhance chronic disease self-management: how can we apply this to stroke? Disabil Rehabil. 2006;28(13-14):841-847. doi:10.1080/09638280500534952

8. Marks R, Allegrante JP. A review and synthesis of research evidence for self-efficacy-enhancing interventions for reducing chronic disability: implications for health education practice (Part II). Health Promot Pract. 2005;6(2):148-156. doi:10.1177/1524839904266792

9. Wade DT, Halligan PW. The biopsychosocial model of illness: a model whose time has come. Clin Rehabil. 2017;31(8):995-1004. doi:10.1177/0269215517709890.

10. Schwarzer R. Measurement of Perceived Self-Efficacy: Psychometric Scales for Cross-Cultural Research. Berlin: Freie Universität Berlin, Institut für Psychologie; 1994.

11. Bandura A. Self-Efficacy: The Exercise of Control. New York: Freeman; 1994.

12. Felton BJ, Revenson TA, Hinrichsen GA. AIS-acceptance of illness scale. In: Juczyński Z, editor. Measurement Tools in Promotion and Health Psychology. Warsaw: Laboratory of Psychological Tests of Polish Psychological Association; 2001:158-167.

13. Yesavage JA, Brink TL, Rose TL, et al. Development and validation of a geriatric depression screening scale: a preliminary report. J Psychiatr Res. 1982;17(1):37-49. doi:10.1016/0022-3956(82) 90033-4

14. Mahoney F, Barthel D. Functional evaluation: the Barthel Index. $M d$ Med J. 1965;14:61-65.

15. Lawton MP, Brody EM. Assessment of older people: self-maintaining and instrumental activities of daily living. Gerontologist. 1969;9(3 Part 1):179-186. doi:10.1093/geront/9.3_Part_1.179

16. Collen FM, Wade DT, Robb GF, Bradshaw CM. The Rivermead Mobility Index: A further development of the Rivermead Motor Assessment. International Disability Studies. 1991;13(2):50-54. doi:10.3109/03790799109166684

17. Stanisz A. Przystępny Kurs Statystyki z Zastosowaniem STATISTICA PL Wyd. StatSoft, Kraków; 2007.

18. Melchior H, Beuscher C, Thorenz A, et al. Self-efficacy and fear of cancer progression during the year following diagnosis of breast cancer. Psychooncology. 2013;22:39-45.

19. Rodkjaer L, Chesney MA, Lomborg K, et al. HIV-infected individuals with high coping self-efficacy are less likely to report depressive symptoms: across-sectional study from Denmark. Int $J$ Infect Dis. 2014;22:67-72. doi:10.1016/j.ijid.2013.12.008

20. Cummings E, Hauser J, Cameron-Tucker H, et al. Enhancing self-efficacy for self-management in people with cystic fibrosis. Stud Health Technol Inform. 2011;169:33-37.

21. Schmitt MM, Goverover Y, Deluca J, et al. Self-efficacy as a predictor of self-reported physical, cognitive, and social functioning in multiple sclerosis. Rehabil Psychol. 2014;59(1):27-34. doi:10. $1037 / \mathrm{a} 0035288$ 
22. Korpershoek C, van der Bijl J, Hafsteinsdottir TB. Self-efficacy and its influence on recovery of patients with stroke: A systematic review. $J A d v$ Nurs. 2011;67(9):1876-1894. doi:10.1111/j.1365-2648.2011.05659.x

23. Gillham S, Endacott R. Impact of enhanced secondary prevention on health behaviour in patients following minor stroke and transient ischaemic attack: a randomized controlled trial. Clin Rehabil. 2010;24(9):822-830. doi:10.1177/0269215510367970.

24. Lieber AC, Hong E, Putrino D, Nistal DA, Pan JS, Kellner CP. Nutrition, Energy Expenditure, Dysphagia, and Self-Efficacy in Stroke Rehabilitation: A Review of the Literature. Brain Sci. 2018;8(12):218. doi:10.3390/brainsci8120218

25. Nott M, Wiseman L, Seymour T, Pike S, Cuming T, Wall G. Stroke self-management and the role of self-efficacy. Disabil Rehabil. 2019;1-10. doi:10.1080/09638288.2019.1666431

26. Torrisi M, De Cola M, Buda A, et al. Self-Efficacy, Poststroke Depression, and Rehabilitation Outcomes: is There a Correlation? J Stroke Cerebrovasc Dis. 2018;27(11):3208-3211. doi:10.1016/j. jstrokecerebrovasdis.2018.07.021

27. Volz M, Voelkle MC, Werheid K. General self-efficacy as a driving factor of post-stroke depression: a longitudinal study. Neuropsychol Rehabil. 2018;4:1-13.
28. Robinson-Smith G, Johnston M, Allen J. Self-care self-efficacy, quality of life, and depression after stroke. Archives of Physical Medicine and Rehabilitation. 2000;81(4):460-464. doi:10.1053/mr.2000.3863

29. Volz M, Möbus J, Letsch C, Werheid K. The influence of early depressive symptoms, social support and decreasing self-efficacy on depression 6 months post-stroke. J Affect Disord. 2016;206:252-255. doi:10.1016/j.jad.2016.07.041

30. Svendsen HA, Teasdale TW. The influence of neuropsychological rehabilitation on symptomatology and quality of life following brain injury: a controlled long-term follow-up. Brain Injury. 2006;20(12):1295-1306. doi:10.1080/02699050601082123

31. Intercollegiate Stroke Working Party. National Clinical Guideline for Stroke. Vol. 28; 2016.

32. Mazurek J. Holistic physiotherapy or psycho-physio-therapy. Part III: human being in physiotherapy - from biomedical approach to holistic model via humanistic concept. Fizjoterapia. 2009;17(4):87-93.

33. Szczepańska-Gieracha J, Kowalska J, Salamon-Krakowska K, Ochnik M, Jaworska-Burzyńska L. Role of Family in the Process of Rehabilitation of Older Adults Hospitalized in a Nursing Home. Top Geriatr Rehabil. 2017;33(2):127-132. doi:10.1097/TGR.00000 00000000147
Psychology Research and Behavior Management

\section{Publish your work in this journal}

Psychology Research and Behavior Management is an international, peer-reviewed, open access journal focusing on the science of psychology and its application in behavior management to develop improved outcomes in the clinical, educational, sports and business arenas. Specific topics covered in the journal include: Neuroscience, memory and decision making; Behavior modification and management; Clinical
Dovepress

applications; Business and sports performance management; Social and developmental studies; Animal studies. The manuscript management system is completely online and includes a very quick and fair peer-review system, which is all easy to use. Visit http://www. dovepress.com/testimonials.php to read real quotes from published authors. 